\title{
Effect of Chain Length and Saturation of the Fatty Acids in Dietary Triglycerides on Lipid Metabolism in Wistar Rats
}

Chaturi M. Senanayake, Harsha Hapugaswatta, Gangi Samarawickrama, Nimanthi Jayathilaka, Kapila Seneviratne

Submitted date: 06/05/2020 - Posted date: 08/05/2020

Licence: CC BY-NC-ND 4.0

Citation information: Senanayake, Chaturi M.; Hapugaswatta, Harsha; Samarawickrama, Gangi; Jayathilaka, Nimanthi; Seneviratne, Kapila (2020): Effect of Chain Length and Saturation of the Fatty Acids in Dietary Triglycerides on Lipid Metabolism in Wistar Rats. ChemRxiv. Preprint.

https://doi.org/10.26434/chemrxiv.12251519.v1

Dietary fatty acids are associated with lipid health. We investigated the effect of the chain length and the degree of saturation of fatty acids in dietary triglycerides on serum lipid profiles and hepatic lipid metabolism in Wistar rats. Fat component of the basal diet (soybean oil) was replaced with fats with fatty acids of different chain lengths and saturation and the serum lipids were monitored for 150 days. Principal component (PC) analysis of serum lipid components were related to chain length and saturation using second order polynomial regression analysis. The combined effect of chain length and saturation on PC 1 scores were evaluated by multiple regression analysis. Variation of lipid parameters cannot be well-explained by chain length or saturation alone. Consistent with the formation of large amounts of lipid droplets in the liver, expression of sterol regulatory element binding protein -2 (SREBP2) and peroxisome proliferator-activated receptors (PPARa) involved in hepatic lipid metabolism showed significant $(\mathrm{P}<0.05)$ downregulation in margarine diet group and SREBP2 in dairy butter diet group compared to the control group. Average chain length of fatty acids in triglycerides has a higher influence on the quality of serum lipid parameters than the average degree of saturation of fatty acids.

File list (4)

Manuscript.pdf (831.36 KiB) view on ChemRxiv • download file Supplemetary Tables.pdf (294.44 KiB) view on ChemRxiv - download file view on ChemRxiv - download file 
Effect of chain length and saturation of the fatty acids in dietary triglycerides on lipid metabolism in Wistar rats

Chathuri M Senanayake ${ }^{\mathrm{a} 1}$, Harsha Hapugaswatta ${ }^{\mathrm{a}}$, Gangi R Samarawickrama ${ }^{\mathrm{a}}$, Nimanthi Jayathilaka ${ }^{a^{*}}$ and Kapila N. Seneviratne $\mathrm{a}^{\mathrm{a}^{*}}$

aDepartment of Chemistry, Faculty of Science, University of Kelaniya, Kelaniya, Sri Lanka.

${ }^{1}$ Present address: Department of Biosystems Technology, Faculty of Technology, University of Sri Jayewardenepura, Sri Lanka.

*Corresponding authors at: Department of Chemistry, University of Kelaniya, Kelaniya, Sri Lanka. Tel.: $9412903263,9412903256$. 


\begin{abstract}
Dietary fatty acids are associated with lipid health. We investigated the effect of the chain length and the degree of saturation of fatty acids in dietary triglycerides on serum lipid profiles and hepatic lipid metabolism in Wistar rats. Fat component of the basal diet (soybean oil) was replaced with fats with fatty acids of different chain lengths and saturation and the serum lipids were monitored for 150 days. Principal component (PC) analysis of serum lipid components were related to chain length and saturation using second order polynomial regression analysis. The combined effect of chain length and saturation on PC 1 scores were evaluated by multiple regression analysis. Variation of lipid parameters cannot be well-explained by chain length or saturation alone. Consistent with the formation of large amounts of lipid droplets in the liver, expression of sterol regulatory element binding protein -2 (SREBP2) and peroxisome proliferator-activated receptors (PPAR $\alpha$ ) involved in hepatic lipid metabolism showed significant $(\mathrm{P}<0.05)$ downregulation in margarine diet group and SREBP2 in dairy butter diet group compared to the control group. Average chain length of fatty acids in triglycerides has a higher influence on the quality of serum lipid parameters than the average degree of saturation of fatty acids.

Key words: Antioxidant activity; Dietary fatty acids; Fatty acid chain length; Gene expression; Lipid profiles; Saturated fat
\end{abstract}




\section{Introduction}

Fatty acid composition is the main decisive factor of health effects of fats. Many studies have categorized fatty acids based on saturation or unsaturation in the evaluation of health effects. Saturated fatty acids are considered to confer negative health effects such as elevated serum cholesterol levels and increased risk of coronary heart disease (CVD). Monounsaturated fatty acids have beneficial effects on lipid profiles ${ }^{1}$. Epidemiological studies and clinical trials indicate that n-3- polyunsaturated fatty acids (n-3-PUFA) are known to cause beneficial effects on cardiovascular disease, though there are different opinions ${ }^{2}$. Clinical trials with healthy young adults have indicated that the diets rich in the long chain saturated fatty acid, stearic acid, did not increase plasma total cholesterol (TC) and low-density lipoprotein (LDL) levels ${ }^{3}$. Fatty acid chain lengths have also been considered in many nutritional studies. Serum high density lipoprotein (HDL) level of healthy humans decreased with the increasing chain length of fatty acids greater than C14:0 while those consuming fatty acid-rich meals with C12:0 + C14:0 showed the highest serum HDL levels ${ }^{4}$. A trial conducted with healthy young women using ${ }^{13} \mathrm{C}$ labeled palmitic (16:0), stearic (18:0) and oleic acids (18:1) indicate that the excretion of ${ }^{13} \mathrm{C}$ label in stool vary stearic>oleic>palmitic while ${ }^{13} \mathrm{C}$ labeled breath was similar in all cases over a $24 \mathrm{~h}_{\text {period }} 5$. Though this study indicates that fatty acid chain length and saturation affect the absorption and metabolic disposal of fatty acids, the range of chain length used in the study is C16-C18 and the range of unsaturation used is saturated to monounsaturated. An early study on fatty acid chain length using synthetically prepared ${ }^{14} \mathrm{C}$ carboxyl labeled saturated fatty acids with $\mathrm{C} 4, \mathrm{C} 8, \mathrm{C} 12, \mathrm{C} 16$ chain lengths indicate that the rate of metabolism decreases with the chain length of fatty acids ${ }^{6}$. 
Degree of saturation and chain length of fatty acids regulate the expression of genes involved in lipid metabolism in the liver. Glycolytic and lipogenic enzymes and the enzymes that are involved in fatty acid oxidation are regulated by $\mathrm{PUFA}^{7}$. Medium chain triglycerides are known to suppress hepatic necroptotic and inflammatory signaling pathways ${ }^{8}$. Saturated fatty acids are known to regulate the activity of peroxisome proliferator activated receptors, sterol regulatory binding proteins (SREBPs) and liver $\mathrm{X}$ receptor 9 .

It is challenging to use natural food sources with necessary variation to evaluate the effect of fatty acid chain length and saturation on metabolism. Most of the studies conducted to investigate the effect of chain length and degree of saturation of dietary fatty acids on lipid profiles have been conducted with synthetic triglycerides and fatty acids with limited range of chain length variation. It is also challenging to work with oils of plant origin for the studies involving the nutritional effects of chain length and degree of saturation due to the presence of varying amounts of natural phenolic substances that can affect the quality of lipid parameters. For example, Morus nigra L. leaves containing high phenolic and flavonoid contents decreased serum cholesterol and triglycerides and normalized lipoproteins ${ }^{10}$. Medium chain fatty acids have also been shown to improve of the absorption of small polar molecules such as phenolic antioxidants and flavonoids compared to long chain fatty acids in the intestine ${ }^{11}$.

None of these studies have evaluated the relative contribution of the fatty acid chain length and the degree of saturation on the metabolism of lipids. In the present study, we carefully selected the sources of fat to vary the chain length and saturation while keeping the antioxidant levels roughly similar and conducted a comprehensive study on the effect of chain length and degree of saturation on lipid profiles and expression of selected genes in the liver in order to assess the effect on lipid metabolism. 


\section{Results}

Fatty acid composition of the sources of fat in the diets. Instead of categorizing fatty acids as long-chain, medium-chain and short-chain, average chain length (ACL) was introduced to represent the chain length and average degree of saturation (ADS) was introduced to represent the saturation of fatty acids for PC analysis. ACL and ADS of the fat contents in different diets given in Table 1 shows that the ACL ranges roughly from C13 to C18 and ADS ranges from $17 \%$ to $91 \%$.

Table 1. Characteristics of the fatty acids from the sources of fat in the diets

\begin{tabular}{lllll} 
& & & \multicolumn{2}{l}{ Chain length of fatty acids } \\
\hline Fat & ACL & ADS $(\%)$ & C6-C12 \% & C14-C18 \% \\
component & (C atoms) & & & \\
\hline Soybean oil & 17.78 & 17 & 0.92 & 99.76 \\
Coconut fat & 13.13 & 91 & 59.21 & 40.96 \\
Dairy butter & 16.03 & 73 & 8.82 & 91.23 \\
Margarine & 16.25 & 60 & 12.89 & 87.43 \\
\hline
\end{tabular}

Serum lipid profiles. Serum lipid profiles of rats fed with control diet (CD), coconut fat diet, (CFD), diary butter diet (DBD) and margarine diet (MD) are given in Table 2. A significant $(\mathrm{p} \leq 0.05)$ increase in serum total cholesterol was observed on day 150 in rats fed with all the diets compared to their day 0 levels. However, the total cholesterol levels in CD and CFD fed groups were significantly $(\mathrm{p} \leq 0.05)$ lower compared to DBD and MD fed groups. HDL levels of CD and MD diets groups on day 150 showed no significant difference compared to those on day 0 . HDL levels significantly $(\mathrm{p} \leq 0.05)$ increased in CFD and DBD diet groups on day 150 compared to day 0 . A significant $(\mathrm{p} \leq 0.05)$ increase of $\mathrm{LDL}$ in $\mathrm{CD}, \mathrm{DBD}$ and $\mathrm{MD}$ groups and a significant decrease $(p \leq 0.05)$ of LDL in CFD group were observed on day 150 compared to day 0 . TG levels showed increases in relatively shorter feeding periods in CFD and DBD diet groups. 
However, TG levels of CD and CFD diet groups were significantly ( $\mathrm{p} \leq 0.05)$ lower compared to DBD and MD diet groups on day 150. Body weights and heart weights of the CFD, DBD and MD were not significantly different from those of $\mathrm{CD}$ at the end of the dietary intervention.

Table 3 shows that Eigen values are higher than 1 for PC1 explaining $63 \%$ of the variance and close to 1 for PC2 having a cumulative variance of $87 \%$ for PC1 and PC2. Score plot of first two principal components (PC1 and PC2) given in Fig. 1 shows that PC1 scores were positively loaded by TC, LDL and TG and negatively by HDL. From the relationship between PC1 scores and ACL (Fig 2a) and ADS (Fig 2b), it is evident that intermediate values of ACL and ADS registered higher PC1 scores. This indicates that intermediate values of ACL and ADS are characterized by high HDL. Multiple regression relationship of PC1 score against ACL and ADS is given by the equation, $\mathrm{PC} 1=-30.38+1.589 \mathrm{ACL}+0.884$ ADS. This result indicates that the chain length contributes more to lipid parameters than saturation.

Table 2. Serum lipid profile of rats received control, coconut spread, dairy butter and margarine diets

\begin{tabular}{|c|c|c|c|c|c|}
\hline \multirow{2}{*}{$\begin{array}{l}\text { Lipid } \\
\text { Parameter }\end{array}$} & \multirow{2}{*}{ Day } & \multicolumn{4}{|c|}{ Lipid content (mg/dL) } \\
\hline & & CD & CFD & DBD & MD \\
\hline Total & 0 & $68.83 \pm 3.14^{\mathrm{aq}}$ & $72.89 \pm 10.39^{\mathrm{aq}}$ & $71.12 \pm 5.87^{\mathrm{ar}}$ & $71.12 \pm 5.33^{\mathrm{ar}}$ \\
\hline \multirow[t]{4}{*}{ cholesterol } & 30 & $71.17 \pm 6.59^{\mathrm{bq}}$ & $74.56 \pm 2.38^{\mathrm{bq}}$ & $84.32 \pm 6.73^{\mathrm{aq}}$ & $78.70 \pm 6.49^{b q}$ \\
\hline & 90 & $75.36 \pm 3.04^{\mathrm{cp}}$ & $76.60 \pm 8.47^{\mathrm{cp}}$ & $90.58 \pm 4.73^{\mathrm{ap}}$ & $81.56 \pm 4.97^{\mathrm{bq}}$ \\
\hline & 120 & $75.12 \pm 2.44^{\mathrm{bp}}$ & $78.80 \pm 4.10^{\mathrm{bp}}$ & $94.92 \pm 3.39^{\text {ap }}$ & $90.49 \pm 4.97^{\text {ap }}$ \\
\hline & 150 & $77.42 \pm 6.97^{\mathrm{cp}}$ & $82.49 \pm .41^{\mathrm{bp}}$ & $91.16 \pm 6.41^{\text {ap }}$ & $94.47 \pm 5.55^{\text {ap }}$ \\
\hline \multirow[t]{5}{*}{ HDL } & 0 & $27.81 \pm 4.64^{\text {ap }}$ & $29.16 \pm 6.87^{\mathrm{aq}}$ & $27.47 \pm 4.49^{\mathrm{aq}}$ & $28.10 \pm 2.17^{\text {ap }}$ \\
\hline & 30 & $25.05 \pm 4.27^{\mathrm{bp}}$ & $34.25 \pm 4.02^{\mathrm{aq}}$ & $18.82 \pm 5.46^{\mathrm{br}}$ & $26.20 \pm 4.13^{\mathrm{bp}}$ \\
\hline & 90 & $27.08 \pm 7.51^{\mathrm{bcp}}$ & $43.88 \pm 4.30^{\text {ap }}$ & $32.36 \pm 9.33^{\mathrm{bp}}$ & $22.26 \pm 7.37^{\mathrm{cp}}$ \\
\hline & 120 & $27.08 \pm 4.01^{\mathrm{cp}}$ & $41.44 \pm 1.54^{\mathrm{ap}}$ & $32.00 \pm 4.09^{\mathrm{bp}}$ & $28.88 \pm 4.23^{\mathrm{cp}}$ \\
\hline & 150 & $25.42 \pm 5.46^{\mathrm{cp}}$ & $39.84 \pm 1.39^{\text {ap }}$ & $31.33 \pm 0.90^{\mathrm{bp}}$ & $26.14 \pm 4.56^{\mathrm{cp}}$ \\
\hline \multirow[t]{5}{*}{ LDL } & 0 & $17.00 \pm 5.17^{\mathrm{aq}}$ & $18.76 \pm 5.77^{\text {ap }}$ & $20.72 \pm 6.65^{\mathrm{aq}}$ & $20.04 \pm 6.13^{\mathrm{aq}}$ \\
\hline & 30 & $22.24 \pm 8.36^{\mathrm{bp}}$ & $11.26 \pm 5.31^{\mathrm{cq}}$ & $34.88 \pm 10.98^{\text {ap }}$ & $30.07 \pm 6.57^{\mathrm{ap}}$ \\
\hline & 90 & $21.59 \pm 8.19^{\text {ap }}$ & $9.90 \pm 4.68^{\mathrm{bq}}$ & $22.23 \pm 9.81^{\mathrm{aq}}$ & $26.89 \pm 8.82^{\mathrm{ap}}$ \\
\hline & 120 & $17.34 \pm 4.60^{\mathrm{bq}}$ & $10.75 \pm 3.00^{\mathrm{cq}}$ & $24.05 \pm 4.58^{\mathrm{aq}}$ & $24.17 \pm 3.25^{\mathrm{ap}}$ \\
\hline & 150 & $20.41 \pm 2.49^{\mathrm{bp}}$ & $12.98 \pm 4.91^{\mathrm{cq}}$ & $29.04 \pm 8.59^{\mathrm{ap}}$ & $30.94 \pm 8.69^{\text {ap }}$ \\
\hline \multirow[t]{2}{*}{ Triglycerides } & 0 & $120.06 \pm 8.05^{\text {aq }}$ & $119.17 \pm 6.09^{\mathrm{ar}}$ & $114.74 \pm 9.86^{\mathrm{ar}}$ & $119.41 \pm 12.73^{\mathrm{aq}}$ \\
\hline & 30 & $119.39 \pm 12.72^{b q}$ & $145.06 \pm 13.10^{\mathrm{ap}}$ & $131.02 \pm 11.30^{\mathrm{bq}}$ & $112.19 \pm 10.73^{b q}$ \\
\hline
\end{tabular}


Mean of 7 rats \pm SD

$\begin{array}{lllll}90 & 133.47 \pm 14.93^{\text {bq }} & 124.63 \pm 9.71^{\text {bq }} & 179.92 \pm 29.66^{\text {ap }} & 162.04 \pm 30.17^{\text {ap }} \\ 120 & 162.38 \pm 14.88^{\text {bp }} & 128.64 \pm 5.98^{\text {cq }} & 194.35 \pm 15.90^{\text {ap }} & 187.20 \pm 15.98^{\text {ap }} \\ 150 & 149.46 \pm 11.61^{\text {bp }} & 150.72 \pm 13.32^{\text {bq }} & 177.77 \pm 18.69^{\text {ap }} & 186.95 \pm 19.16^{\text {ap }}\end{array}$

Different letters $(a, b$ and $c)$ indicate a significant difference in rows $(p \leq 0.05)$

Different letters $(p, q$ and $r)$ indicate a significant difference in columns $(p \leq 0.05)$

Table 3. Principal component analysis

\begin{tabular}{lll}
\hline & PC1 & PC2 \\
\cline { 2 - 3 } Eigen value & 2.5203 & 0.9433 \\
Proportion & 0.630 & 0.236 \\
Cumulative & 0.630 & 0.866 \\
Coefficients & & \\
Se TC 150 & 0.556 & 0.339 \\
Se HDL & -0.323 & 0.864 \\
Se LDL & 0.580 & -0.142 \\
Se TG & 0.500 & 0.345 \\
\hline
\end{tabular}

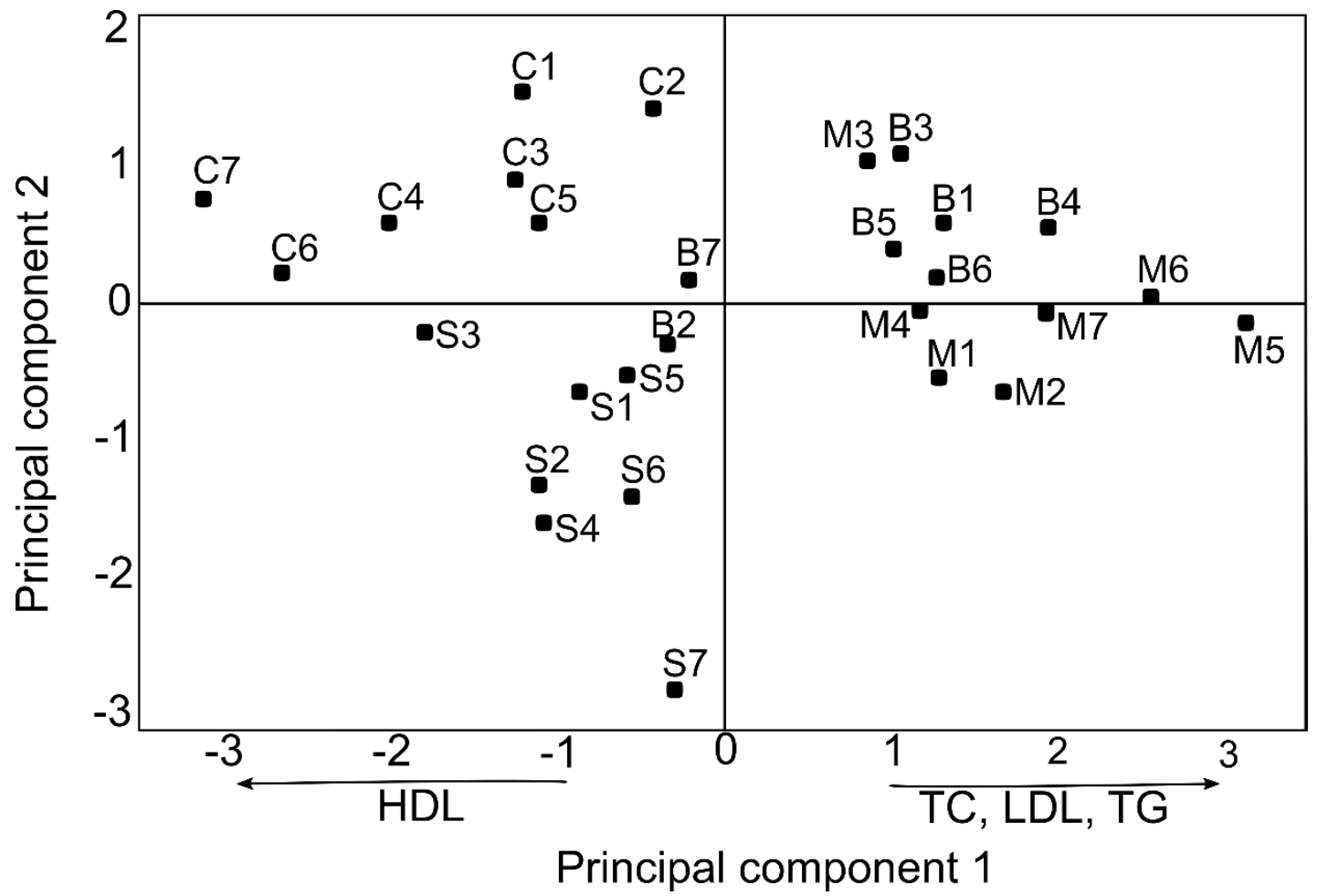

Fig. 1. Score plot of serum total cholesterol, HDL, LDL and triglyceride $(C=C F D, S=C D, B=D B D$, $\mathrm{M}=\mathrm{MD}$ ) 


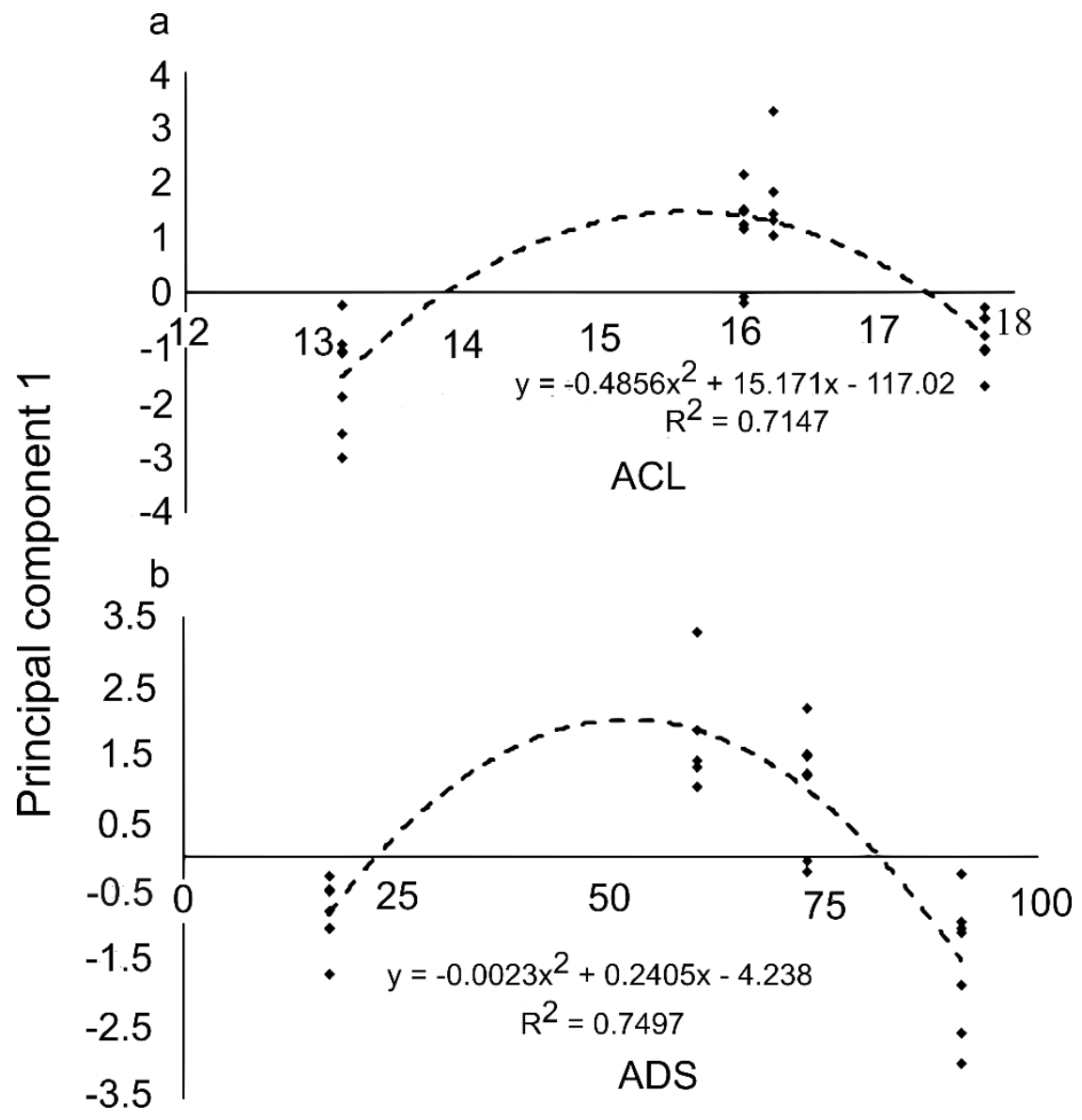

Fig. 2. Second order polynomial relationship of PC1 scores with a) ACL and b) ADS

Liver histology. Liver plays a central role in lipid metabolism, serving as the center for lipoprotein uptake, formation, and export to the circulation and thus regulate the circulating lipid levels. Altered hepatic lipid metabolism leads to alterations in circulating lipid levels. Therefore, we assessed the effect of dietary intervention on the liver histology. H \& E stained liver sections are 
given in Supplementary Fig. 1. After 150 days of feeding, least number of vacuoles (fat depositions) in the liver cells was observed in the CFD group and the number of vacuoles in CFD group was not significantly different from that of CD group (Table 4). However, DBD and MD fed rats showed a significantly higher $(\mathrm{P}<0.05)$ number of vacuoles per liver cell compared to the CD or CFD group. The calculated area of the vacuoles was consistent with these findings.

Table 4. Lipid vacuole characteristics in liver tissues

\begin{tabular}{lll}
\hline Diet group & Number of vacuoles/cell & Area of vacuoles/cell (ImageJ) \\
\hline CD & $2.95 \pm 1.48^{\mathrm{a}}$ & $2135.64 \pm 916.61^{\mathrm{a}}$ \\
CFD & $2.72 \pm 1.31^{\mathrm{a}}$ & $2018.59 \pm 781.38^{\mathrm{a}}$ \\
DBD & $3.91 \pm 1.33^{\mathrm{b}}$ & $4110.07 \pm 1313.90^{\mathrm{b}}$ \\
MD & $5.95 \pm 2.14^{\mathrm{c}}$ & $3812.38 \pm 1384.08^{\mathrm{b}}$ \\
\hline
\end{tabular}

Different letters $(\mathrm{a}, \mathrm{b}$ and $\mathrm{c})$ indicate a significant difference in columns $(\mathrm{p} \leq 0.05)$

Gene expression analysis in liver. The expression of the transcription factor, SREBP2, that regulates synthesis and cellular uptake of fatty acids in lipid metabolism showed a significant down regulation $(\mathrm{P}<0.05)$ in expression between the rats fed with $\mathrm{CD}$ (largely composed of long-chain polyunsaturated fatty acids) and the rats fed with DBD or MD (largely composed of long-chain saturated fatty acids) (Fig. 3a). Similarly, PPAR $\alpha$, the predominant isoform of the nuclear receptors for fatty acids in the liver also showed a significant downregulation $(\mathrm{P}<0.05)$ of expression in the rats fed with MD compared to those fed with CD (Fig. 3b). Both Low density lipoprotein receptor (LDLR), a direct target of SREBP2 and ATP-binding cassette sub family A member 1 (ABCA1) involved in reverse cholesterol transport did not show a significant 
differential expression in the rats fed with CFD, DBD or MD compared to rats fed with CD (Fig. $3 c, 3 d)$.

Interestingly, the rats fed with CFD with high medium-chain saturated fatty acid composition did not show any significant differential expression from the rats fed with CD. In fact, rats fed with CFD showed significant $(\mathrm{P}<0.05)$ differential expression from the counterparts fed with long chain saturated fatty acid containing diets (DBD or MD). Rats fed with MD showed significant downregulation of expression $(\mathrm{P}<0.05)$ in SREBP2, PPAR $\alpha$ and LDLR compared to rats fed with CFD. LDLR expression is also significantly downregulated $(\mathrm{P}<0.01)$ in rats fed with $\mathrm{DBD}$, compared to rats fed with CFD. ABCA1, on the other hand, is significantly upregulated $(\mathrm{P}<0.05)$ in the rats fed with DBD compared to the rats fed with CFD. DBD and MD groups only showed significant $(\mathrm{P}<0.01)$ differential expression in the level of expression in PPAR $\alpha$. In fact, the expression level of PPAR $\alpha$ in the MD fed group is significantly downregulated compared to all other diet groups $(\mathrm{P}<0.05)$. 

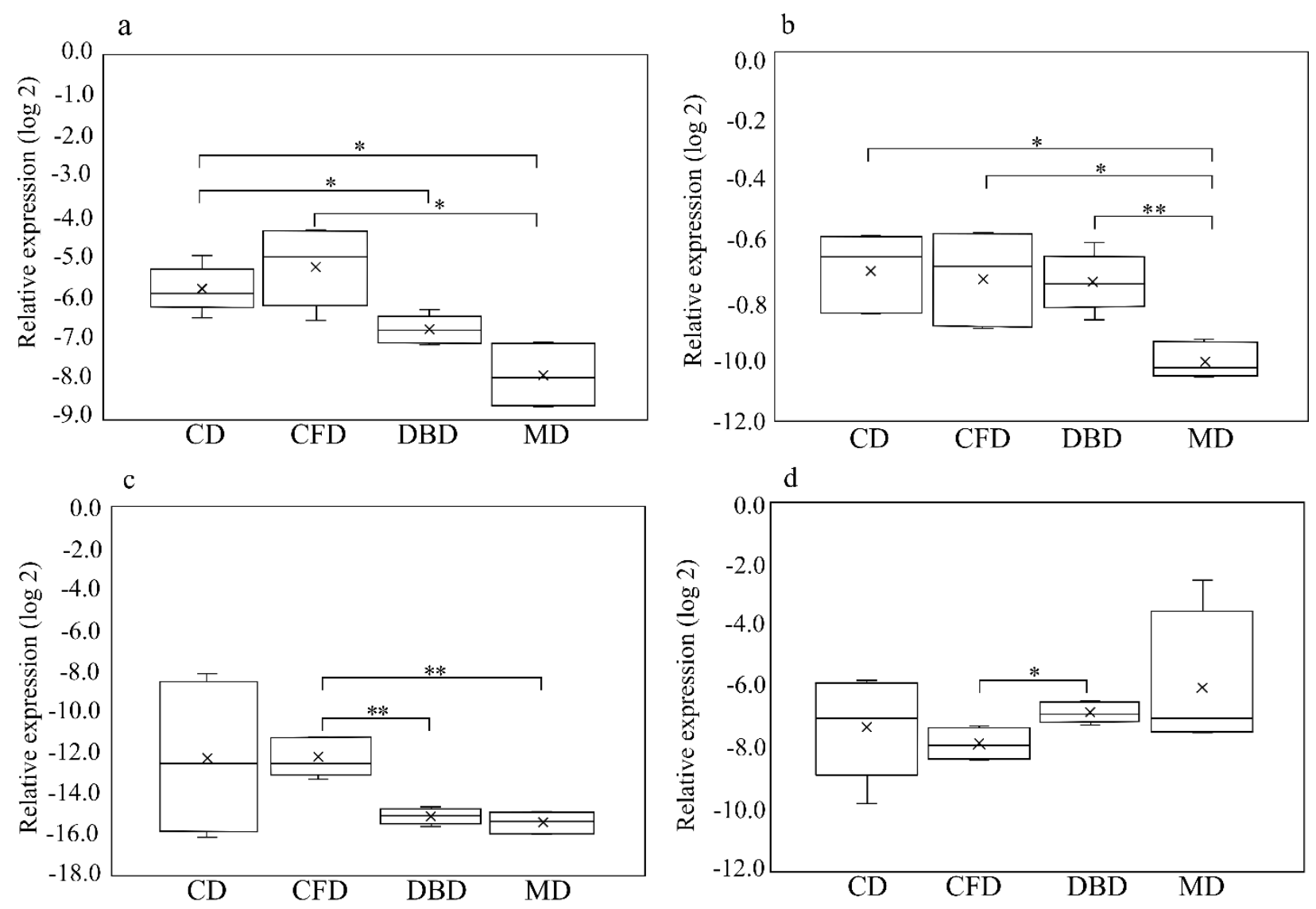

Fig. 3. Relative gene expression in liver tissue from rats fed with diets containing different sources of dietary fat. Relative expression of a) SREBP2 b) PPAR $\alpha$ c) LDLR and d) ABCA1 in rats fed with CD, CFD, DBD, and MD presented as log values to the base $2\left(\log _{2}\right)$ based on $2^{-\Delta C q}$ values against glyceraldehyde 3-phosphate dehydrogenase (GAPDH). * $\mathrm{P}<0.05$ and $* * \mathrm{P}<0.01$ based on $\triangle \mathrm{Cq} \pm \mathrm{SEM}$ using Welch's ANOVA test with post hoc Games-Howell test.

Antioxidant activity. Previous studies have shown that the efficiency of the intestinal absorption of phenolic antioxidants vary with the nature of fatty acids in the diet and the improvement of intestinal absorption of phenolic compounds is reflected by the improvement of serum antioxidant capacity $^{11}$. Therefore, total phenolic contents of the rat diets were analyzed. In addition, the serum antioxidant activities of the feeding groups were monitored over 150 days using 2,2'-azino-bis (3- 
ethylbenzothiazoline-6-sulphonic acid) (ABTS) assay and 1,1- Diphenyl- 2- picrylhydrazyl (DPPH) radical scavenging activity assay. Total phenolic contents ( $\mathrm{mg} \mathrm{g}^{-1}$ as gallic acid) of CD, CFD, DBD and MD are 2.95 $\pm 0.08,3.30 \pm 0.10,3.15 \pm 0.11$ and $3.14 \pm 0.13$ respectively. There is no significant difference among the values of total phenol contents. Both trolox equivalent antioxidant capacity (TEAC) and DPPH radical scavenging activities showed significant $(\mathrm{p} \leq 0.05)$ variations with the fat group as well as with time during initial period of feeding (Supplementary Table 1). However, there was no significant difference of TEAC or DPPH radical scavenging activity among feeding groups after 90 days. In addition, none of the diets significantly affected the hepatic expression of antioxidant response genes, glutathione peroxidase (GPX), catalase (CAT) and Copper, zinc superoxide dismutase (CuZn-SOD) in Wistar rats (Supplementary Fig. 2).

\section{Discussion}

Many studies classify fats as saturated, monounsaturated, polyunsaturated, medium chain and long chain based on the major fatty acids. However, fats contain mixtures of fatty acids with a range of different chain lengths and saturations. Therefore, ACL and ADS was introduced in PC analysis to represent all the fatty acids in a source of fat. In the present study, soybean oil used as the source of fat in CD was replaced by different sources of fat with fatty acids of different chain lengths and degree of saturation. Having a wider range of ACL (C13-C18) and ADS (17\%-91\%) of fatty acids in the triglycerides of the diets used in the present study allows to get a better idea of the effect of chain length and saturation on the lipid profiles. Dietary fatty acids affect the quality of serum lipids. Meals containing mainly saturated fat with relatively shorter fatty acid chain lengths such as lauric acid and myristic acid increased post meal TC, TAG and HDL levels more quickly compared to meals containing mainly saturated fat with longer chain fatty acids such as palmitic and stearic acids ${ }^{4}$. Diets enriched with medium chain fatty acids significantly increase serum HDL 
levels compared to diets enriched with long chain saturated fatty acids ${ }^{12}$. Although it is wellestablished that saturation and chain length affect the serum lipid quality, individual contributions of saturation and chain length have not been evaluated. PC analysis followed by second order polynomial regression analysis of PC1 with ACL and ADS gives curves of similar shape with, PC1 increasing and then decreasing with the ACL and ADS. Since fats with ADS around 40 and 80 etc. do not exist, this regression analysis has a limited number of values for the degree of saturation. Similarly, since a wide range of naturally occurring fatty acids of various chain lengths do not exist, the regression analysis is also limited by the limited amount of data generated for dietary sources of fat with a wide range of chain lengths. Multiple regression analysis indicates that the contribution of ACL to PC1 is twice as much as the contribution of ADS to PC1 suggesting that the contribution of the chain length of the dietary fats to serum lipid quality is more important than the degree of saturation. For this purpose, it is necessary to collect more data on the ACL and ADS of the fat contents of widely consumed diets in different regions of the world and correlate the resultant compositions with lipid profiles.

Liver is the major site which regulates cholesterol levels in the body. It regulates the synthesis of both cholesterol and triacylglycerol and removes the cholesterol by converting in to bile salts which can be eliminated in the feces ${ }^{9}$. Hepatic steatosis or a significant accumulation of fat in the liver is observed in the rats treated with long-chain saturated fatty acid rich diets, DBD and MD. These findings are consistent with the reported literature where saturated fat (usually referred to as long chain saturated fat) can be cut down to manage non-alcoholic fatty liver disease ${ }^{13}$. In agreement with our findings, medium chain fatty acids which also have a high degree of saturation show a dose-dependent reduction in steatosis and stimulate fatty acid beta oxidation 
resulting in beneficial effects on fatty liver disease ${ }^{14}$. Reports also indicate omega-3 PUFA may also decrease liver fat ${ }^{15}$. Consistent with these observations, DBD and MD groups with higher long chain saturated fat contents compared to $\mathrm{CD}$ and $\mathrm{CFD}$ diets showed significantly $(\mathrm{P}<0.05)$ higher amount of lipids in the form of vacuoles in liver sections (Table 4, Supplementary Fig. 1) suggesting that medium chain fatty acid rich saturated fat has similar contribution to dietary health as polyunsaturated long chain fatty acids. Therefore, it is critical to account for the ACL of the source of fat in addition to the ADS. However, our study is the first report on the combined effect of the chain lengths and the degree of saturation on the deposition of fat in the liver, the lipid profile or regulation of fatty acid metabolism.

Liver plays a major role in regulating the availability of lipid to the other tissues of the body by modulating lipid synthesis and the uptake and secretion of lipoproteins. Dietary fatty acids are known to alter a number of pathways involved in lipid metabolism while more focus has been on polyunsaturated fatty acids. In the present study, expression levels of several targets involved in the metabolism of fatty acids were tested. SREBPs are transcription factors that regulate synthesis and cellular uptake of fatty acids ${ }^{16}$. SREBP2 is responsible for activating genes involved in cholesterol synthesis. Cholesterol accumulation in the liver inhibits the maturation of SREBP2 at the endoplasmic reticulum, thus limiting the availability of transcriptionally active SREBP2 ${ }^{9}$. SREBP2 expression is significantly downregulated $(\mathrm{P}<0.05)$ in the groups fed with DBD and MD containing mainly saturated fatty acids with long ACL compared to the control group fed with a CD consisting of polyunsaturated fatty acids with long ACL. Both DBD and MD groups also showed a significantly $(\mathrm{P}<0.05)$ higher amount of vacuoles in the hepatic tissue sections suggesting a role for saturated fatty acids with long chain length in differentially regulating cellular uptake and cholesterol synthesis associated with SREBP2 expression in the 
liver. SREBP2/PNPLA8 axis has been shown to improve non-alcoholic fatty liver disease through activation of autophagy ${ }^{17}$. SREBP2 driven autophagy is associated with controlling hepatic triglyceride accumulation in mice fed with a high fat diet and decrease in cellular triglycerides ${ }^{17,18}$. Dysregulated autophagy is associated with the steatosis and nonalcoholic fatty liver disease. Hepatic steatosis involves the accumulation of triacyl glycerol in hepatocytes making small and large droplets of fat. Increased expression of SREBP2 alleviates autophagic dysfunction in non-alcoholic fatty lever disease resulting from hepatic accumulation of fat ${ }^{18}$. In fact, rats fed with CD and CFD did not show a differential expression of SREBP2 or increased hepatic accumulation of fats as evident from the $\mathrm{H} \& \mathrm{E}$ stained liver sections, suggesting that saturated fat diets with medium ACL and polyunsaturated diets with long ACL may regulate the hepatic gene expression in a similar manner. Rats fed with CD and CFD also did not show a significant difference in the serum triglycerides.

SREBP2 regulate LDLR expression through direct interaction with a sterol-regulatory element (SRE) in the promoter of the receptor gene. There is a strong correlation between SREBP2 and LDLR mRNA across all diets ${ }^{9}$. LDLR mediate the uptake of LDL circulating in the blood stream and transport them into cells. LDL is broken down to release cholesterol inside the cells for membrane synthesis. Most LDLRs are expressed in the liver. An increase in the plasma LDL levels could be observed due to suppression of hepatic LDLR. Conversely, whenever LDLR are induced, the plasma LDL levels fall ${ }^{19}$. Expression level of LDLR is significantly $(\mathrm{P}<0.05)$ downregulated in both DBD and DB groups while CD and CFD showed no significant difference in expression. These findings are consistent with the role of SREBP2 which also did not show a significant differential expression between $\mathrm{CD}$ and $\mathrm{CFD}$ and a significant $(\mathrm{P}<0.05)$ downregulation of expression in the rats fed with DBD and MD. Further, the serum LDL levels showed a 
corresponding significant $(\mathrm{P}<0.05)$ increase in $\mathrm{DBD}$ and $\mathrm{MD}$ due to decreased hepatic clearance. Saturated fatty acids are known to promote nonalcoholic fatty liver and increase plasma LDL levels ${ }^{20}$. Consistent with these reports, rats fed with DBD and MD show a significant $(\mathrm{P}<0.05)$ increase in hepatic accumulation of fat as indicative of NAFLD and serum LDL levels. However, contrary to the reported effects of medium chain fatty acids (C12 - C16) on the serum LDL levels, the serum LDL levels of the rats fed with CFD composed of mainly saturated medium chain fatty acids (ACL $\sim \mathrm{C} 13$ and ADS 90\%) showed a significant $(\mathrm{P}<0.05)$ decrease albeit no differential expression of LDLR or steatosis.

Peroxisome proliferator-activated receptors (PPARs) are nuclear receptors for fatty acids regulated by fatty acids ${ }^{21}$. PPAR $\alpha$ is a ligand activated transcriptional factor and it is the predominant isoform in the liver among the PPARs9. PPAR $\alpha$ regulates the expression of genes involved in fatty acid beta oxidation and is a major regulator of energy homeostasis ${ }^{22}$. PPAR $\alpha$ expression has been reported to reduce the development of oxidative stress in alcoholic liver disease when treated with polyenephosphatidylcholine through downregulation of ROS-generating enzymes such as ethanol-inducible cytochrome P450 2E1 (CYP2E1), acyl-CoA oxidase, and NADPH oxidase ${ }^{23}$. Polyunsaturated fatty acids are known to downregulate the expression of genes involved in the fatty acid synthesis. The mode of action of most of the hepatic lipid metabolism pathways by polyunsaturated fatty acids is through regulation of transcription factors including SREBP2 and PPAR $\alpha^{9}$. Downregulation of PPAR $\alpha$ gene also supports the high fat accumulation in the liver. In the present study, MD showed a significant $(\mathrm{P}<0.05)$ downregulation of PPAR $\alpha$ gene in the liver compared to animals fed with CD containing mainly polyunsaturated long chain fatty acids, CFD containing mainly medium chain saturated fatty acids and DBD containing mainly long chain saturated fatty acids, suggesting that MD group may be more susceptible to nonalcoholic liver 
disease (fatty liver). Consistent with these observations, MD group show the largest number and area of fat vacuoles in the liver as well as a significant $(\mathrm{P}<0.05)$ increase in serum LDL levels and triglycerides as shown in Tables 4 and 2. High fat depositions/contents in rats fed with DBD and MD as shown in the cross sections of liver tissues compared to rats fed with CD and CFD with no significant differential expression suggests that downregulation of SREBP2 and PPAR $\alpha$ is connected to the fatty acid composition in the diet.

ABCA1 plays a key role in moving the excess cellular cholesterol and phospholipids from cell membranes to HDL particles which is the first step of the reverse cholesterol transport pathway ${ }^{24}$. Plasma HDL plays a key role in maintaining cholesterol homeostasis. ABCA1 showed a significant upregulation in DBD group compared to the CFD group suggesting that medium-chain saturated fatty acids present in the CFD may regulate hepatic expression of genes involved in fatty acid metabolism in a manner unlike the long-chain saturated fatty acids but rather in a manner similar to soy oil consisting of long-chain poly unsaturated fatty acids.

Phenolic antioxidants present in plant-based lipids have beneficial effects on serum lipid profiles and serum antioxidant status. Due to the similar total phenol contents of the diets, adjustments of total phenol contents were not attempted in the present study and any effect of phenolic substances on lipid profiles were assumed to be similar for all the diets. The results of present study indicate that long term feeding of diets with different fat compositions but with equal quantities of phenolic substances will not change the antioxidant activities among different fat groups.

Oxidative stress caused by reactive oxygen species plays a major role in progression of nonalcoholic fatty liver disease ${ }^{25}$. Reactive oxygen species are generated in the liver by mitochondria, 
peroxisomes, cytochrome P-450, reduced nicotinamide adenine dinucleotide oxidase, cyclooxygenase, and lipoxygenase. Our previous studies have shown a significant increase in the absorption of phenolic antioxidants by medium chain fatty acids ${ }^{11}$. Enhanced absorption of antioxidants and the resultant effects on the level of expression in the oxidative stress reponse genes may contribute to the significant differences in accumulation of fat in liver observed among the diet groups. CuZn-SODs catalyze the dismutation of superoxide $\left(\mathrm{O}_{2}-\right)$ into oxygen $\left(\mathrm{O}_{2}\right)$ and hydrogen peroxide $\left(\mathrm{H}_{2} \mathrm{O}_{2}\right)$, while CAT and GPX remove the $\mathrm{H}_{2} \mathrm{O}_{2}$ generated from the superoxide dismutase reaction. However, no significant changes in the expression of liver antioxidant response genes were observed in the $\mathrm{CFD}, \mathrm{DBD}$ and $\mathrm{MD}$ groups compared to the $\mathrm{CD}$ group suggesting that the antioxidants present in the diets, absorption of antioxidants or the changes to the antioxidant response in the liver does not contribute to the observed effects of the accumulation of fat in the liver.

In conclusion, triglycerides containing mainly medium chain fatty acids with the highest degree of saturation affect the lipid profiles, deposition of fat in the liver and regulation of expression of genes involved in fatty acid metabolism in a manner similar to the triglycerides containing mainly polyunsaturated fats with long chain fatty acids. The long chain saturated fats with less saturated fat on the other hand affect the lipid profile, fat deposition in the liver and the expression of genes involved in fatty acid metabolism in the liver in a manner significantly different from the polyunsaturated fats with long chain fatty acid. Diet contains triglycerides with different degrees of saturation and chain lengths. Therefore, the combined effect of the ACL and the ADS may be more useful in understanding the effect of the nature of fatty acids in the diet on fatty acid metabolism and nutritional health. 


\section{Materials and Methods}

Chemicals. DPPH and ABTS diammonium salt were purchased from Sigma (St. Louis, MO). All other chemicals were purchased from either Sigma or Fluka (Buchs, Switzerland).

Diets. The basal diet referred as CD is a semi synthetic diet that contains soybean oil (3\%) as the source of fat (Supplementary Table 2). For test diets, soybean oil in CD was replaced by coconut fat spread, diary butter and margarine to prepare CFD, DBD and MD respectively. Pellets of the diets were prepared for feeding purposes.

Fatty acid composition. Fat source $(5.0 \mathrm{~g})$ was mixed with $25 \mathrm{~mL}$ of chloroform:methanol mixture $(2: 1, \mathrm{v} / \mathrm{v})$ and shaken in an orbital shaker for $20 \mathrm{~min}$. The solution was decanted and another two successive extractions were performed using the same solvent ( $25 \mathrm{~mL}$ each). The extracts were combined, dried over anhydrous sodium sulphate, filtered and the solvent was evaporated in a rotary evaporator $\left(37^{\circ} \mathrm{C}\right)$. Fatty acid methyl esters of the fat extracts and soybean oil were prepared and subjected to gas chromatography (GC) analysis as reported ${ }^{26}$. ACL and the ADS of the fatty acids were calculated based on the fatty acid composition.

Animal study design. Seven weeks old male Wistar rats (240-300 g) were selected from the Medical Research Institute, Colombo, Sri Lanka. The animals were housed at $25 \pm 1{ }^{\circ} \mathrm{C}$ with a 12 $\mathrm{h}$ light and dark cycle. Rats were acclimatized to the CD for 6 days and randomly assigned into experimental groups. The first group was fed with CD. Second, third and fourth groups were fed with CFD, DBD and MD respectively and feeding experiments were continued for 150 days. Rats were given ad libitum access to food and water throughout the experimental period and monitored daily. The rats were fasted for 10-12 $\mathrm{h}$ and blood was drawn from the tail vein on the day before feeding the experimental diets (day 0) and during feeding experiments (day 30, 90, 120 and 150). Serum was separated by centrifugation (400 g, $10 \mathrm{~min}$ ) at room temperature (RT). Plasma from blood collected in EDTA tubes were separated similarly. At the end of the feeding experiments, 
the animals were subjected to barbiturate euthanasia. The experimental protocol for the rat study was approved by the Ethics Review Committee of Faculty of Medical Sciences, University of Sri Jayewardenepura, Sri Lanka (Application number 25/16).

Serum lipid profiles. Serum TC, HDL and triglyceride levels were determined using the test kit method provided by G Cell (Beijing Strong Biotechnologies, Inc, China). Serum LDL was determined using the Friedewald equation:

$\mathrm{LDL}=$ Total cholesterol $-\mathrm{HDL}-($ Triglycerides/5)

Histology. Liver specimens were fixed in $4 \%$ buffered formalin for 24 to $48 \mathrm{~h}$. Tissue sections were embedded in a paraffin mold ${ }^{27}$. Paraffin embedded sections were cooled on ice and separated from the mold and sectioned at a thickness of $5 \mu \mathrm{m}$ using a microtome (Accu-Cut SRM 200 Rotary Microtome, Sakura, Japan). Tissue sections were deparaffinized using xylene on microscopic slides and hydrated by passing through decreasing concentrations of alcohol baths $(100 \%, 90 \%$, $80 \%$, and $70 \%$ ). The tissue sections were stained with hematoxylin for $10 \mathrm{~min}$ and rinsed with tap water for 5 min until nucleus of the sections stained purple. Sections were then stained with eosin for $30 \mathrm{~s}$ until cytoplasm was stained pink and rinsed with tap water for 1-5 min. The tissue sections were mounted in DPX mounting media, covered with a cover slip and observed under a trinocular microscope (Optica, Italy) at $100 \times$ magnification with oil immersion. Images were taken using a 5 MP digital camera (Optica 5, Italy).

An area that covers five cells was selected and vacuoles were counted manually. Area of the vacuoles were measured using Image $\mathrm{J}$ software (Version 1.50i).

Gene expression analysis. Liver tissues stored at $-80{ }^{\circ} \mathrm{C}$ were thawed on ice. Tissue $(30 \mathrm{mg})$ was ground under liquid nitrogen and ice cold lysis buffer $(300 \mu \mathrm{L})$ (Ambion Life Technologies, USA) was added and mixed rapidly. $1 / 10^{\text {th }}$ volume of miRNA homogenate was added to the lysate, mixed 
by inverting the tube, incubated on ice for $10 \mathrm{~min}$ and transferred to a tube containing Dow Corning high vacuum silicone grease (70 $\mu \mathrm{L}$ ) (Sigma-Aldrich, USA) which was previously spun at 16,000 g for 15 min at $4{ }^{\circ} \mathrm{C}$. Acid-phenol-chloroform $(300 \mu \mathrm{L})$ (Ambion Life Technologies, USA) was added, mixed by inverting and centrifuged at $15,000 \mathrm{~g}$ for $5 \mathrm{~min}$ at RT. The upper aqueous layer was separated into a new grease tube prepared as stated. Chloroform $(300 \mu \mathrm{L})$ was added, mixed by flicking the tube, kept on ice for 2 min and centrifuged at $16,000 \mathrm{~g}$ for 5 min at $4{ }^{\circ} \mathrm{C}$ to remove residual phenol. The top layer was transferred to a new tube. RNA was precipitated using $30 \mu \mathrm{L}$ of $3 \mathrm{M}$ sodium acetate ( $\mathrm{pH}$ 5.2) and ice-cold isopropanol (1 volume). The contents were chilled on ice for $30 \mathrm{~min}$ and centrifuged at $16,000 \mathrm{~g}$ for $30 \mathrm{~min}$ at $4{ }^{\circ} \mathrm{C}$. The pellet was washed with ice cold ethanol $(75 \% \mathrm{v} / \mathrm{v}, 1 \mathrm{~mL})$ twice. Each time the contents were centrifuged at 16,000 $\mathrm{g}$ for $10 \mathrm{~min}$ at $4{ }^{\circ} \mathrm{C}$. The pellet was air dried and resuspended in $30 \mu \mathrm{L}$ of DNAse and RNAse free water. Total RNA was treated with DNAse in order to remove genomic DNA contamination using DNA-free DNA removal kit (Ambion Life Technologies, USA). Absorbance values were recorded at 230 $\mathrm{nm}, 260 \mathrm{~nm}$ and $280 \mathrm{~nm}$ to quantify and determine the purity. cDNA was synthesized from total RNA ( $1 \mu \mathrm{g})$ using High-Capacity cDNA Reverse Transcription Kit according to the manufacturers' instructions (Applied Biosystems, USA) and stored at $-20^{\circ} \mathrm{C}$. Gene specific rat primer pairs designed based on published mRNA sequences available in NCBI are shown in Supplementary Table 3. Expression was quantified in triplicate using QuantiTect SYBR Green PCR kit (Qiagen, Germany) in $20 \mu \mathrm{L}$ reaction volume with $2 \mu \mathrm{L}$ cDNA, $200 \mathrm{nM}$ each forward and reverse primers at $60{ }^{\circ} \mathrm{C}$ annealing temperature $(1 \mathrm{~min})$ using StepOne real-time PCR system (Applied Biosystems, USA). The efficiencies of amplification were above $85 \%$ for all primer pairs based on standard curve analysis as previously reported ${ }^{28}$. No-template reactions and melting curve analysis was used to confirm specificity of target amplification. 
Fold change of expression compared to the control soy diet was calculated using $2^{-\Delta \Delta \mathrm{Cq}}$ and presented as $\log _{2}$ values. A difference in expression based on fold change of less than 0.5 between diet groups was considered as downregulation and above 1.5 was considered as upregulation.

Total phenol contents of diets. Dry diet pellets were ground using a kitchen grinder and sieved through a $180 \mu \mathrm{m}$ mesh to obtain a fine powder. Phenolic compounds were extracted to ethanol:water $(70: 30 \mathrm{v} / \mathrm{v}, 2.0 \mathrm{~mL})$ by mixing the powder $(2.0 \mathrm{~g})$ using a vortex at $40 \mathrm{~Hz}$ for $2 \mathrm{~min}$ (twice) and centrifuged at 400g for $10 \mathrm{~min}$. Four successive extractions were performed for each sample and resultant extracts were diluted to $10.0 \mathrm{~mL}$. Total phenol content was determined based on a reported method ${ }^{29}$.

Serum antioxidant activity. ABTS cation free radical decolourization assay was conducted according to a method described ${ }^{30}$. Control was prepared with solvent in place of phenolic extract. Working ABTS solution $(290 \mu \mathrm{L})$, phosphate saline buffer $(9 \mu \mathrm{L})$ and serum $(1 \mu \mathrm{L})$ were mixed. Control was prepared by adding water $(1 \mu \mathrm{L})$ instead of serum. The antioxidant activity was expressed as TEAC. DPPH radical scavenging activity of serum was determined according to a reported method ${ }^{31}$.

The inhibition \% was calculated as follows.

Inhibition $\%=\left[1-\left(\mathrm{A}_{517}\right.\right.$ serum sample/A517 control $\left.)\right] \times 100$

Statistical analysis. Since it was not possible to assume the effect size, the sample size for the dietary intervention study was calculated using the resource equation method as reported ${ }^{32}$. The degree of freedom for analysis of variance (ANOVA), E was estimated to be 20 for four groups with 6 rats each. Seven rats per group were used after accounting for approximately $10 \%$ attrition. All analyses were run in triplicate unless otherwise indicated. All data were tested for normal distribution at $95 \%$ confidence interval using Shapiro-Wilk test where a P>0.05 was determined 
as normal distribution. Homogeneity of variance was tested with Levene's test using IBM SPSS Statistics, 2013 version. Descriptive statistics are given as mean \pm standard deviation. Two sample t-test was carried out for the determination of significant differences $(p<0.05)$ between the means. Data for experimental groups were independently compared by one-way ANOVA. To investigate the underlying pattern of serum lipid profile, principal component (PC) analysis of serum TC, HDL, LDL and TG was performed. PC1 scores were related to ACL and ADS of the fatty acids using second order polynomial regression analysis. Multiple regression analysis was employed to investigate the combined effect of ACL and ADS on PC1 scores. Data analysis was conducted using Minitab (Version 17 for Windows). Statistical significance for differentially expressed targets were determined based on the $\Delta \mathrm{Cq}$ for each sample using Welch's ANOVA test followed by Games-Howell post hoc tests for heterogeneous variances for pairwise comparisons. Continuous variables were expressed as median and interquartile range (IQ $25-75)$. All differences were considered statistically significant at $\mathrm{p} \leq 0.05$.

\section{References}

1. Wharburg, U. What are the health effects of fats? Eur. J. Nutr. 43, 6-11 (2004).

2. Ander, B. P., Dupasquier, C. M. C., Prociuk, M.A. \& Pierce, G. N. Polyunsaturated fatty acids and their effects on cardiovascular disease. Exp. Clin. Cardiol. 8, 164-172 (2003).

3. Kris-Etherton, P. M. Effects of chain length of saturated fatty acids on plasma total, LDLand HDL-cholesterol levels. Eur. J. Lipid Sci. Tech. 95, 448-552 (1993).

4. Karupaiah, T., Tan, C. H., Chinna, K. \& Sundram, K. The chain length of dietary saturated fatty acids affects human postprandial lipemia. J. Am. Coll. Nutr. 30, 511-521 (2011). 
5. Jones, A. E., Stolinski, M., Smith, R. D., Murphy, J. L. \& Wootton, S. A. Effect of fatty acid chain length and saturation on the gastrointestinal handling and metabolic disposal of dietary fatty acids in women. Brit. J. Nutr. 81, 37-43 (1999).

6. Kirschner, S. L. \& Harris, R. S. The effects of chain length on the metabolism of saturated fatty acids by the rat. J. Nutr. 73, 397-402 (1961).

7. Raclot, T. \& Oudart, H. Selectivity of fatty acids on lipid metabolism and gene expression. Proc. Nutr. Soc. 58, 633-646.

8. Zhang L. et al. Medium-chain triglycerides attenuate liver injury in lipopolysaccharidechallenged pigs by inhibiting necroptotic and inflammatory signaling pathways. Int. J. Mol. Sci. 19, 3697; https://doi.10.3390/ijms19113697 (2018).

9. Vallim, T. \& Salter, A. M. Regulation of hepatic gene expression by saturated fatty acids. Prostag. Leukotr. Ess. 82, 211-218 (2010).

10. Zeni, A. B. et al. Evaluation of phenolic compounds and lipid-lowering effect of Morus nigra leaves extract. An. Acad. Bras. Cienc. 89, 2805-2815 (2017).

11. Prasadani, W. C., Senanayake, C. M., Jayathilaka, N., Ekanayake, S. \& Seneviratne, K. N. Effect of three edible oils on the intestinal absorption of caffeic acid: An in vivo and in vitro Study. PLoS One 12, e0179292, https://doi.10.1371/journal.pone.0179292 (2017).

12. Panth, N., Abbott, K. A., Dias, C. B., Wynne, K. \& Garg, M. L. Differential effects of medium- and long-chain saturated fatty acids on blood lipid profile: a systematic review and meta-analysis. Am. J. Clin. Nutr. 108, 675-687 (2018).

13. Dyson, J. K., Anstee, Q. M. \& McPherson, S. Non-alcoholic fatty liver disease: a practical approach to treatment. Frontline Gastroenterol 5, 277-286 (2014). 
14. Ronis, M. J. et al, Medium chain triglycerides dose-dependently prevent liver pathology in a rat model of non-alcoholic fatty liver disease. Exp. Biol. Med. (Maywood). 238, 151$162(2013)$.

15. Yan, J-H., Guan, B-J., Gao, H-Y. \& Peng, X-E. Omega-3 polyunsaturated fatty acid supplementation and non-alcoholic fatty liver disease. A meta-analysis of randomized controlled trials. Medicine (Baltimore) 97, 37(e12271), https://doi.10.1097/MD.0000000000012271 (2018).

16. Madison, B. B. Srebp2: A master regulator of sterol and fatty acid synthesis. J. Lipid Res. 57, 333-335 (2016).

17. Kim, K-Y. et al. SREBP-2/PNPLA8 axis improves non-alcoholic fatty liver disease through activation of autophagy. Sci. Rep. 6, 35732, https://doi.org/10.1038/srep35732 (2016).

18. Cheng, H., Deng, X. \& Xu, K. Increased expression of sterol regulatory element binding protein-2 alleviates autophagic dysfunction in NAFLD. Int. J. Mol. Med. 41, 1877-1886 (2018).

19. Brown, M. S. \& Goldstein, J. L. Lipoprotein metabolism in the macrophage: Implications for cholesterol deposition in atherosclerosis. Ann. Review Biochem. 52, 223-261 (1983).

20. Sampath, H. \& Ntambi, J. M. Polyunsaturated fatty acid regulation of genes of lipid metabolism. Аnпu. Rev. Nutr. 25, 317-340 (2005).

21. Desvergne, B.\& Wahli, W. Peroxisome proliferator-activated receptors: Nuclear control of metabolism. Endocr. Rev. 20, 649-688 (1999). 
22. Van Raalte, D. H., Li, M., Pritchard, P. H. \& Wasan, K. M. Peroxisome proliferatoractivated receptor (PPAR)-: A pharmacological target with a promising future. Pharm. Res. 21, 1531-1538 (2004).

23. Abdelmegeed, M. A. et al., PPAR $\alpha$ expression protects male mice from high fat-induced nonalcoholic fatty liver. J. Nutr. 141, 603-610 (2011).

24. Singaraja, R. R. et al. Increased ABCA1 activity protects against atherosclerosis. J. Clin. Invest. 110, 35-42 (2002).

25. Polimeni, L. et al. Oxidative stress: New insights on the association of nonalcoholic fatty liver disease and atherosclerosis. World J. Hepatol. 7, 1325-1336 (2015).

26. Seneviratne, K. N., Kotuwegedara, R. T. Canarium zeylanicum seed oil :an edible oil with beneficial qualities. Int. J. Food. Sci. Technol. 4, $792-798$ (2009).

27. Altunkaynak, Z. Effects of high fat diet induced obesity on female rat livers (A histochemical study). Eur. J. Gen. Med. 2, 100-109 (2005).

28. Hapugaswatta, H., Amarasena, P., Premaratne, R., Seneviratne, K.N. \& Jayathilaka, N. Differential expression of microRNA, miR-150 and enhancer of zeste homolog 2 (EZH2) in peripheral blood cells as early prognostic markers of severe forms of dengue. $\mathrm{J}$. Biomed. Sci.; 27, 25; doi: 10.1186/s12929-020-0620-z (2020).

29. Singleton, V. L. \& Rossi, J. A. Colorimetry of total phenolics with phosphomolybdicphosphotungstic acid reagents. Am. J. Enol. Viticult. 16, 144-158 (1965).

30. Re, R. et al. Antioxidant activity applying an improved ABTS radical. Free Radic. Biol. Med. 26, 1221-1237 (1999).

31. Senanayake, C. M., Hapugaswatta, H., Jayathilaka, N. \& Seneviratne, K. N. Phenolic extracts of the leaves of Psidium guineense Sw. improve the shelf life of sunflower oil 
and baked cake and antioxidant status of Wistar rats. J. Food Biochem. 42, e12632, https://doi.org/10.1111/jfbc.12632 (2018).

32. Charan, J. \& Kantharia, N.D. How to calculate sample size in animal studies? J. Pharmacol. Pharmacother. 4, 303-306 (2013).

\section{Data availability}

All the data used to support the findings of this study are included in the article and in supplementary materials.

\section{Acknowledgments}

This work was supported by grants from National Science Foundation, Sri Lanka (RG/2015/AG/03, RG/2015/EQ/02) and University of Kelaniya Sri Lanka (Grant $\mathrm{RP} / 03 / 02 / 06 / 01 / 2017)$.

\section{Author contributions}

C.M.S. carried out animal studies and data analysis. H.H. carried out gene expression analysis. G.R.S. carried out liver histology analysis. K.N.S., N.J. conceptualized, designed experiments, supervised and wrote the original manuscript. All authors read and approved the final version of the manuscript.

\section{Competing interests}

The authors declare no competing interests. 
Supplementary Table 1

Serum antioxidant activity of rats

\section{Trolox equivalent antioxidant capacity $(\mu \mathrm{mol} / \mathrm{L})$}

\begin{tabular}{lllll}
\hline Day & Control & Coconut spread & Dairy butter & Margarine \\
0 & $15.40 \pm 2.44^{\mathrm{aq}}$ & $15.43 \pm 1.90^{\mathrm{ar}}$ & $15.9 \pm 1.40^{\mathrm{aq}}$ & $16.59 \pm 3.02^{\mathrm{aq}}$ \\
30 & $13.11 \pm 1.48^{\mathrm{cq}}$ & $19.57 \pm 1.58^{\mathrm{aq}}$ & $16.13 \pm 1.64^{\mathrm{bq}}$ & $14.00 \pm 1.26^{\mathrm{cq}}$ \\
90 & $19.29 \pm 1.59^{\mathrm{bp}}$ & $21.89 \pm 1.78^{\mathrm{ap}}$ & $19.29 \pm 3.61^{\mathrm{ap}}$ & $21.46 \pm 3.49^{\mathrm{ap}}$ \\
120 & $19.90 \pm 1.12^{\mathrm{ap}}$ & $22.18 \pm 2.77^{\mathrm{ap}}$ & $20.93 \pm 1.94^{\mathrm{ap}}$ & $19.01 \pm 2.29^{\mathrm{ap}}$ \\
150 & $19.98 \pm 1.39^{\mathrm{ap}}$ & $22.38 \pm 2.49^{\mathrm{ap}}$ & $20.53 \pm 2.29^{\mathrm{ap}}$ & $18.45 \pm 2.61^{\mathrm{ap}}$ \\
\hline
\end{tabular}

DPPH radical Scavenging activity (Inhibition \%)

\begin{tabular}{lllll}
\hline 0 & $10.78 \pm 0.71^{\text {ar }}$ & $10.84 \pm 1.11^{\text {ar }}$ & $10.41 \pm 1.09^{\text {ar }}$ & $12.22 \pm 1.92^{\text {ar }}$ \\
30 & $10.33 \pm 0.70^{\text {br }}$ & $17.84 \pm 2.26^{\text {aq }}$ & $14.19 \pm 3.75^{\text {aq }}$ & $16.16 \pm 2.48^{\text {aq }}$ \\
90 & $33.1 \pm 3.65^{\text {ap }}$ & $35.21 \pm 3.10^{\text {ap }}$ & $33.94 \pm 2.70^{\text {ap }}$ & $32.59 \pm 4.97^{\text {ap }}$ \\
120 & $34.78 \pm 5.32^{\text {ap }}$ & $35.96 \pm 5.80^{\text {ap }}$ & $32.93 \pm 2.14^{\text {ap }}$ & $32.85 \pm 3.56^{\text {ap }}$ \\
150 & $30.18 \pm 3.68^{\text {ap }}$ & $32.80 \pm 1.69^{\text {ap }}$ & $30.40 \pm 4.88^{\text {ap }}$ & $31.01 \pm 4.12^{\text {ap }}$ \\
\hline
\end{tabular}

Note. Each data point represents the mean \pm SD $(n=7)$. Different letters ( $a$ and $b)$ indicate a significant difference in rows $(\mathrm{p} \leq 0.05)$. Different letters $(\mathrm{p}, \mathrm{q}$ and $\mathrm{r})$ indicate a significant difference in columns $(\mathrm{p} \leq 0.05)$. 
Supplementary Table 2

Composition of control diet (CD)

\begin{tabular}{ll}
\hline \multicolumn{1}{c}{ Ingredient } & $\begin{array}{c}\text { Amount } \\
\text { g/kg }\end{array}$ \\
\hline Maize meal (60\% protein) & 345 \\
Broken rice & 100 \\
Red rice polished & 25 \\
Rice/ wheat bran & 20 \\
Wheat flour & 169 \\
Fish meal (60\% Protein) & 30 \\
Soya meal (48\% protein) & 160 \\
Molasses/ sugar & 10 \\
Soya oil & 30 \\
Grass powder & 60 \\
Bone meal & 15 \\
Mineral mix & 20 \\
Vitamin mix & 8 \\
Sodium chloride & 4.08 \\
Beta mix E50 & 0.4 \\
DL Methionine & 0.52 \\
Vitamin B & 3 \\
\hline
\end{tabular}


Supplementary Table 3

Rat primers used for Rt-PCR analysis

\begin{tabular}{|c|c|c|}
\hline \multirow{3}{*}{$\begin{array}{l}\text { Target gene } \\
\text { GPX }\end{array}$} & Sequence (5'-3') & Accession number/reference \\
\hline & F- CGGACATCAGGAGAATGGCA & NM_030826.4 \\
\hline & R- GATGTCGATGGTGCGAAAGC & \\
\hline \multirow[t]{2}{*}{ CAT } & F- AGACCCGGATTATGGCCTCC & NM_012520.2 \\
\hline & R- GCCAAACCTTGGTCAGGTCA & \\
\hline \multirow[t]{2}{*}{ CuZn-SOD } & F- AAGCGGTGAACCAGTTGTGG & NM_017050.1 \\
\hline & R- AACATGCCTCTCTTCATCCGC & \\
\hline \multirow[t]{2}{*}{ SREBP2 } & F- CTGTTCGACTAATGGCGGGA & XM_006242079.3 \\
\hline & R-CAGGTGTCTACTTCTCCGTGTT & \\
\hline PPAR $\alpha$ & $\begin{array}{l}\text { F- ATTGGCGTTCGCAGCTGTT } \\
\text { R- AGCACCAATCTGTGATGACAACG }\end{array}$ & NM_013196.1 \\
\hline LDLR & $\begin{array}{l}\text { F- AGAACTGCGGGGCCGAAGACAC } \\
\text { R- AAACCGCTGGGACATAGGCACTCA }\end{array}$ & NM_175762.2 \\
\hline ABCA1 & $\begin{array}{l}\text { F- CGTCCTCCTTGTCATCTCTG } \\
\text { R- TAACTTTCTTTCACTTTCTCGTC }\end{array}$ & NM_178095.2 \\
\hline
\end{tabular}




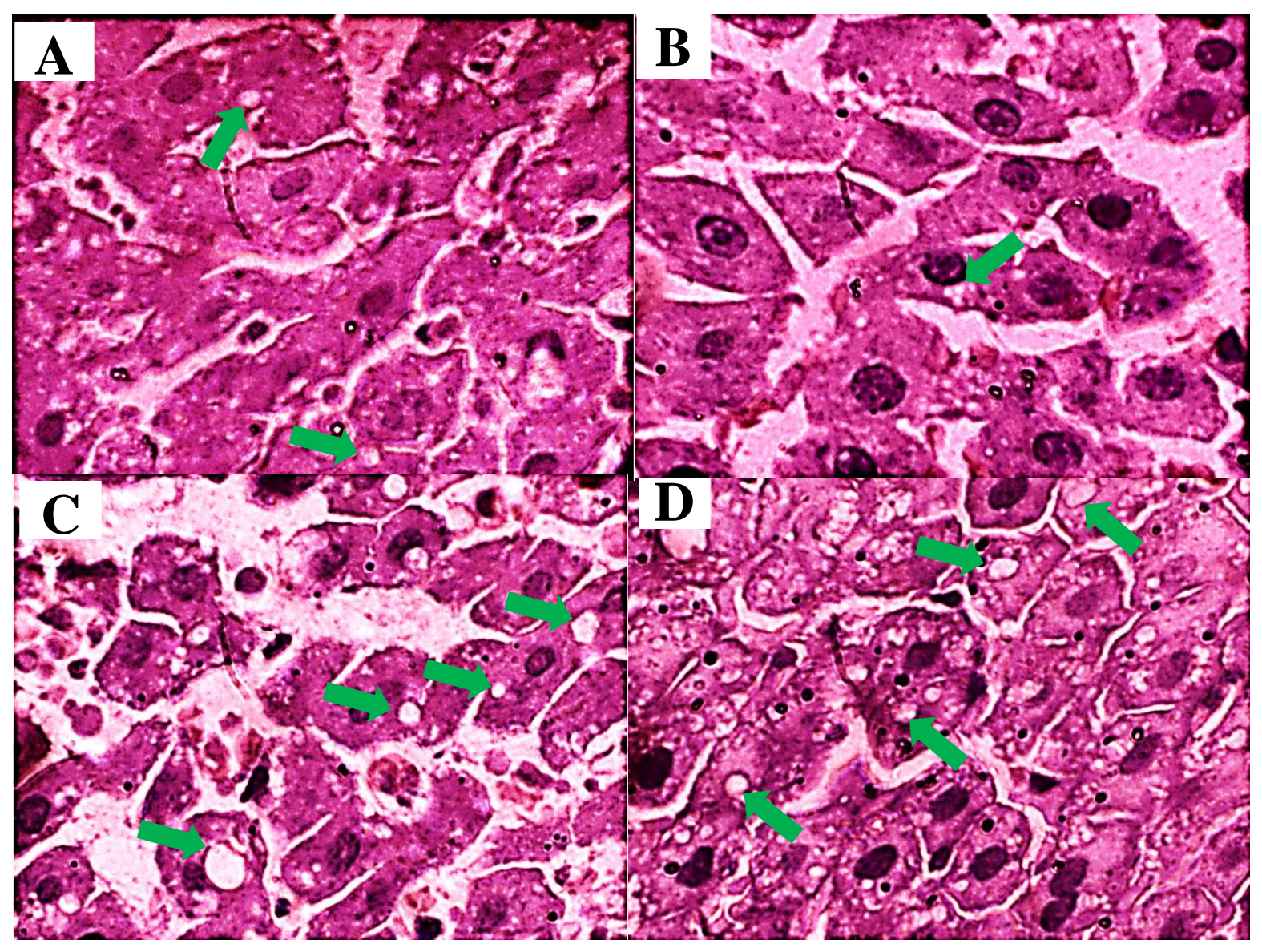

Supplementary Fig.1. H \& E stained liver sections of the rats fed with different diets (Magnification $\times 100)$. (A - CD, B - CFD, C - DBD, D - MD)

$\Rightarrow$ Indicates vacuoles 

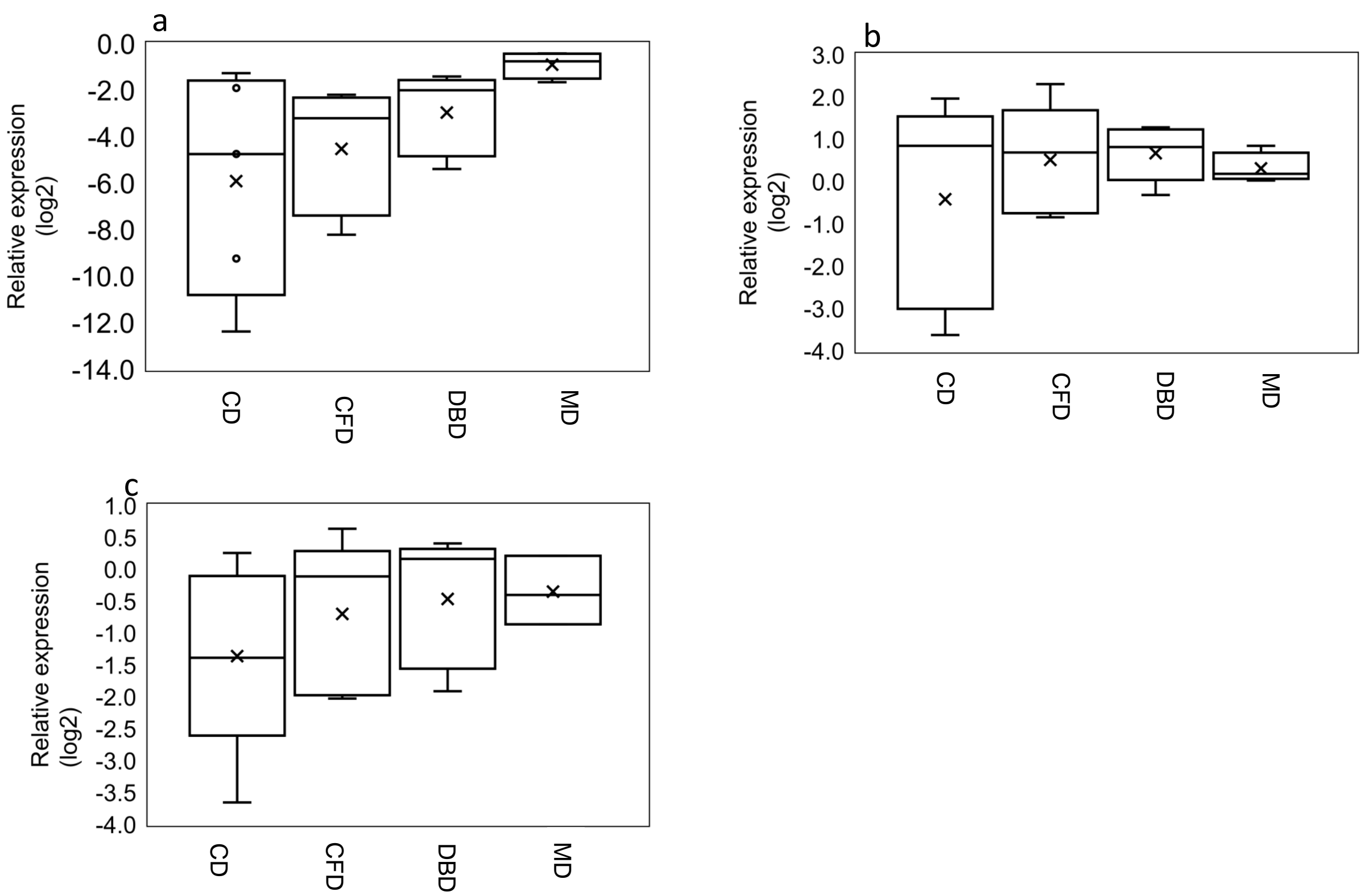

Supplementary Fig. 2. Relative expression of antioxidant response genes in the liver. a)GPX, b) CAT and c) CUZn-SOD 
